\title{
Cigarette smoke induces the expression of Notch3, not Notch1, protein in lung adenocarcinoma
}

\author{
ZHENSHUN CHENG, QIUYUE TAN, WEIJUN TAN and LI ZHANG \\ Department of Respiratory Medicine, Zhongnan Hospital, Wuhan University, Wuhan, Hubei 430070, P.R. China
}

Received July 21, 2014; Accepted March 26, 2015

DOI: $10.3892 / 01.2015 .3329$

\begin{abstract}
The aim of the present study was to determine the effect of cigarette smoke on the expression of Notch proteins in lung adenocarcinoma (LAC). Protein expression levels of Notch1 and Notch3 were analyzed using immunohistochemistry in 102 human LAC specimens. Of these, 52 were obtained from smokers and 50 from non-smokers. In addition, cigarette smoke extract (CSE) at varying concentrations $(1,2.5$ and 5\%) was administered to A549 cells. The expression of Notch1 and Notch3 protein was then detected by western blot analysis at different time points $(0,8,24$ and $48 \mathrm{~h})$. Of the 102 LAC specimens, 42 (41.2\%) were positive for Notch1 and $63(61.8 \%)$ were positive for Notch3. There was no significant difference in the level of Notch1 expression between smokers and non-smokers with LAC ( $\mathrm{P}>0.05)$. The positive rate and staining intensity of Notch3 expression were increased in the smokers compared with the non-smokers $(\mathrm{P}<0.05)$. The expression of Notch3 protein in A549 cells increased in a time- and dose-dependent manner following treatment with CSE, whilst the expression of Notch1 protein appeared stable. The results suggested that cigarette smoke was able to induce the expression of Notch3, not Notch1, protein in LAC. The data revealed an upregulation of Notch3 in LAC following cigarette smoke exposure. Such findings may provide a novel therapeutic target for the treatment of LAC.
\end{abstract}

\section{Introduction}

Lung cancer is a common cause of cancer-associated mortality in men and women worldwide $(1,2)$. Lung adenocarcinoma (LAC), which is classified as a non-small cell lung cancer (NSCLC), is a prevalent subtype, accounting for $\sim 25 \%$ of lung cancers $(2,3)$. Cigarette smoke remains to be a major etiological risk factor for lung cancer $(1,4)$; a

Correspondence to: Dr Li Zhang, Department of Respiratory Medicine, Internal Medicine Building, Zhongnan Hospital, Wuhan University, 169 Donghu Road, Wuhan, Hubei 430070, P.R. China E-mail: lizhang20100127@gmail.com

Key words: lung adenocarcinoma, cigarette smoking, Notch1, Notch3 previous study reported that an increase in the incidence of LAC was correlated with cigarette smoking (5). In addition, several signaling pathway abnormalities in lung cancer have been found to be associated with smoking $(6,7)$. Therefore, further studies that aim to identify the signals activated by smoking-associated carcinogens may aid in the development of targeted therapies for lung cancer patients with a history of smoking.

Notch signaling pathways have been identified to have an important role in the regulation of cell differentiation, proliferation and apoptosis. At present, four Notch receptors (Notch1-4) have been identified in mammals. Of these, a previous study found that an abnormality in the Notch1 and Notch3 signaling pathway contributed to the pathogenesis of lung cancer (8).

Certain studies (9-11) have produced controversial findings concerning the expression of Notch1 protein in NSCLC; Donnem et al (9) and Jiang et al (10) concluded that the overexpression of Notch1 was associated with a poorer prognosis in patients with NSCLC. By contrast, a study by Huang et al (11), which focused on LAC, demonstrated opposing results. With respect to Notch3, Haruki et al (12) found that the positive expression rate was $\sim 37 \%(32 / 87)$. However, Zhou et al (13) and Ye et al (14) identified that the level of Notch3 increased in NSCLC tissues. The deviations in the expression of Notch1 and Notch3 may be due to the heterogeneity of the lung cancer samples. Although the study by Huang et al (11), discussed the association between Notch1 and smoking, this correlation remains uncertain due to the relatively insufficient number of smokers with LAC who were recruited to the study. Therefore, a requirement exists to analyze the effect of cigarette smoke on Notch expression in LAC.

In the present study, the association between Notch1 or Notch3 and smokers with LAC was analyzed by immunohistochemistry. In addition, cigarette smoke extract (CSE) was administered to LAC A549 cells and the expression of Notch1 and Notch 3 were then detected by western blot analysis.

\section{Materials and methods}

Ethics statement. Ethical approval for the present study was granted by the Institutional Ethics Committee of Zhongnan Hospital, Wuhan University (Wuhan, China) and written informed consent was obtained from all patients. 
Patients and tissue samples. In total, 102 LAC samples were obtained from patients diagnosed with pathological stage II LAC at Zhongnan Hospital, Wuhan University between July 2010 and February 2014. Following surgery (consisting of lobar or sublobar resection), these patients were interviewed to determine their smoking history. The tumors were staged according to the seventh edition of the International Association for the Study of Lung Cancer (15) and the histological subtype was graded according to guidelines provided by the World Health Organization (16). The clinical characteristics of the patients are shown in Table I.

The criteria used for the smoker group was as follows (17): i) A smoker prior to the diagnosis of lung cancer; ii) a smoking history of $\geq 10$ packs/year; and iii) a smoking habit of $\geq 10$ cigarettes per day during recent years. The non-smokers were defined as patients who had smoked $<100$ cigarettes during their lifetime and who had been exposed to passive smoking for $<0.5 \mathrm{~h}$ everyday. Ex-smokers were excluded from the present study. All patients had not received chemotherapy or radiotherapy prior to their surgery.

Notch1 and Notch3 immunohistochemistry. Immunostaining of the tumor samples was performed using an avidin-biotinylated horseradish peroxidase $\mathrm{H}$ complex (ABC kit; Vector Laboratories, Inc., Burlingame, CA, USA) according to the manufacturer's instructions. Samples were prepared as follows: Samples $\left(\sim 100 \mathrm{~mm}^{3}\right)$ were cut from each tissue and immersed in $10 \%$ neutral formalin. Following fixation for $24 \mathrm{~h}$, the tissue block was washed in $\mathrm{dH}_{2} \mathrm{O}$ and embedded in paraffin. Prior to experimentation, the samples were cut using a microtome to $\sim 5-\mu \mathrm{m}$ thickness and affixed onto the slides which had been coated by aminopropyl-tri-ethoxy-silane. The slides were then incubated the slides at $60^{\circ} \mathrm{C}$ for $2 \mathrm{~h}$, then placed in a rack and washed as follows: xylene, 2 x $10 \mathrm{~min} ; 100 \%$ ethanol, 2 × $5 \mathrm{~min}$; 95\% ethanol, $5 \mathrm{~min} ; 70 \%$ ethanol, $5 \mathrm{~min} ; 50 \%$ ethanol, $5 \mathrm{~min}$; and finally rinsed in cold tap water. Deparaffinized slides were heated at $98^{\circ} \mathrm{C}$ in $10 \mathrm{mmol} / 1$ citrate buffer (pH 6.0; Boster Biological Technology, Ltd., Wuhan, China) for $30 \mathrm{~min}$. Next, the sections were immersed for $15 \mathrm{~min}$ in methanol containing $0.3 \%$ hydrogen peroxide (Boster Biological Technology, Ltd.) in order to block endogenous peroxidase activity. This was followed by $30 \mathrm{~min}$ of incubation with $5 \%$ blocking horse serum (Beijing Zhongshan Golden Bridge Biotechnology Co., Ltd., Beijing, China)to reduce non-specific binding. Goat polyclonal $\mathrm{IgG}$ antibodies for human Notch1 (C-20; catalog no. sc-6014; Santa Cruz Biotechnology, Inc., Dallas, TX, USA; dilution, 1:200) and Notch3 (M-20; catalog no. sc-7424; Santa Cruz Biotechnology, Inc.; dilution, 1:200) were then added to the slides and incubated at $4^{\circ} \mathrm{C}$ overnight. 3,3'-diaminobenzidine (DAB; Beijing Zhongshan Golden Bridge Biotechnology Co., Ltd.) was used as a chromogen; $100 \mu \mathrm{l}$ DAB was added to each section and monitored under a microscope until the staining developed, which was followed by immersion slides in $\mathrm{dH}_{2} \mathrm{O}$ for $2 \times 3$ min. Slides were then counterstained with hematoxylin (Beijing Zhongshan Golden Bridge Biotechnology Co., Ltd.) for $1 \mathrm{~min}$ and washed in $\mathrm{dH}_{2} \mathrm{O}$ for 2 x $5 \mathrm{~min}$. For the negative controls, primary antibodies were omitted. Each section was analyzed at five randomly
Table I. Characteristics of all patients with lung adenocarcinoma.

\begin{tabular}{lcc}
\hline Characteristic & Smokers & Non-smokers \\
\hline Total, n & 52 & 50 \\
Males/females, $\mathrm{n}$ & $40 / 12$ & $24 / 26$ \\
Mean age, years (range) & $61.2(44-74)$ & $62.4(45-76)$ \\
Smoking history, packs/year & $48.3 \pm 5.6$ & 0 \\
\hline
\end{tabular}

Smoking history values are presented as the mean \pm standard deviation.

selected high-power fields. The sections with $<5 \%$ positive cells were regarded as negative for protein expression. For the positively stained sections, the staining intensity (gray level) of positive granules was assessed using a MIAS-300 image analyzer (Nanjing Aokang Biotechnology Analytical Co., Ltd., Nanjing, China).

Cell culture and reagents. The human LAC A549 cell line (American Type Culture Collection, Manassas, VA, USA) was cultured in RPMI-1640 (Invitrogen Life Technologies, Carlsbad, CA, USA) containing 10\% fetal bovine serum (Invitrogen Life Technologies). The stock environment was maintained at $37^{\circ} \mathrm{C}$ in a humidified $5 \% \mathrm{CO}_{2}$ incubator.

Cell treatment and measurement of cell viability. CSE was prepared as previously described (18). In brief, the smoke obtained from four full-strength Marlboro cigarettes (Marlboro Red; Phillip Morris USA, Pittsburgh, PA, USA) with the filters removed was passed through $100 \mathrm{ml}$ of RPMI-1640 medium. The percentage of CSE was referred to as to the undiluted solution and was considered to be $100 \%$. Subsequently, CSE was adjusted to $\mathrm{pH} 7.4$, filtered through a $0.22-\mu \mathrm{m}$ filter (Sigma-Aldrich, St. Louis, MO, USA) and used within $30 \mathrm{~min}$ of preparation. In total, three different concentrations $(1,2.5$ and $5 \%)$ of CSE diluted with the culture medium were used. Normal RPMI-1640 without CSE was used as a negative control. The A549 cells were cultured in RPMI 1640 medium containing $10 \%$ fetal bovine serum (Invitrogen Life Technologies) for $12 \mathrm{~h}$ at $37^{\circ} \mathrm{C}$ in a humidified atmosphere of $5 \% \mathrm{CO}_{2}$. The cells were then exposed to the CSE for $0 \mathrm{~h}, 8 \mathrm{~h}, 24 \mathrm{~h}$ or $48 \mathrm{~h}$. Subsequently, using a hemocytometer (catalog no. 3200; Hausser Scientific, Horsham, PA, USA), the cell viability was assessed using a Trypan blue (Boster Biological Technology, Ltd.) exclusion test as previously described (19). Briefly, the hemocytometer was filled with a suspension of cells (dilution, 1:1) in $0.4 \%$ Trypan blue solution, and incubated for $2 \mathrm{~min}$ at room temperature. The cells were then counted under a microscope (Tps-N-320m; Shanghai Toposun Industries Co., Ltd., Shanghai, China) to determine the mean number of viable cells (unstained cells) per 1 x $1 \mathrm{~mm}$ square.

Western blot analysis. The samples of the A549 cells were harvested. Equal amounts $(20 \mu \mathrm{g})$ of the proteins were subjected to SDS-PAGE (6\%; Boster Biological Technology, Ltd.) and then transferred to a polyvinylidene fluoride (PVDF) membrane (Sigma-Aldrich). The PVDF membrane was then 

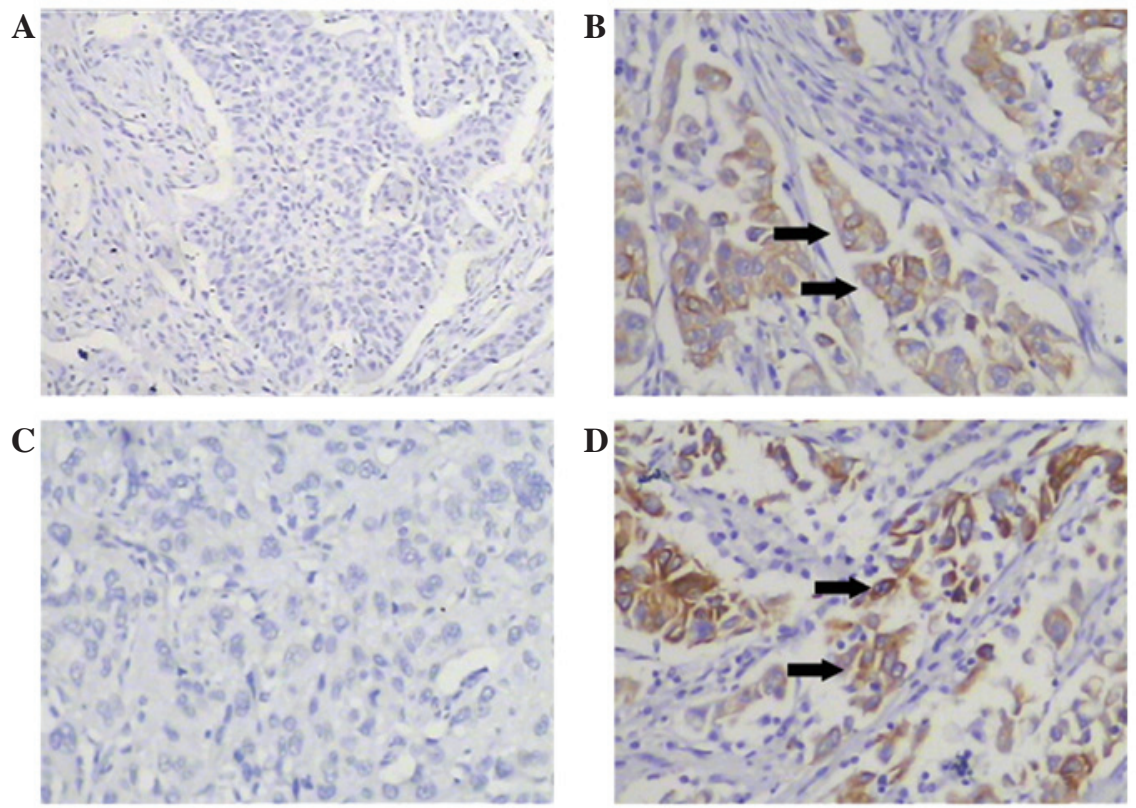

Figure 1. Immunohistochemistry staining for Notch1- and Notch3-positive cells in lung adenocarcinoma tissues of smokers and non-smokers, as determined using 3,3'-diaminobenzidine and hematoxylin staining (magnification, x200). (A) Notch1-positive cells in non-smokers, (B) Notch1-positive cells in smokers, (C) Notch3-positive cells in non-smokers and (D) Notch3-positive cells in smokers. Black arrows show examples of positive staining tumor cells.

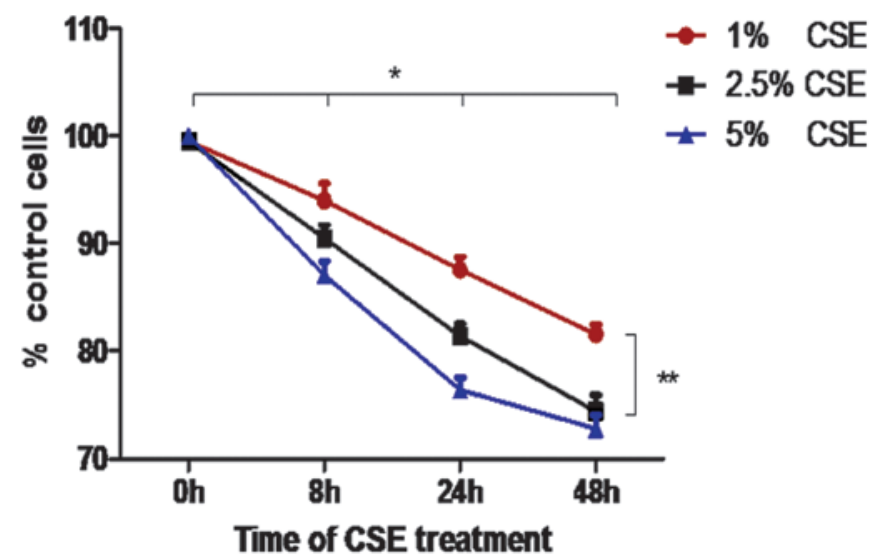

Figure 2. Cell viability of A549 cells assayed by cellular membrane damage assessment using the Trypan Blue exclusion test following $0,8,24$ and $48 \mathrm{~h}$ of treatment with CSE $(1,2.5$ and $5 \%)$. Representative measurements (mean \pm standard deviation) of five distinct sets of data are shown. CSE, cigarette smoke extract. ${ }^{*} \mathrm{P}<0.05$ vs. next time point (in $1 \%$ and $2.5 \%$ CSE groups); ${ }^{* *} \mathrm{P}<0.05$ vs. $1 \% \mathrm{CSE}$ group.

blocked with phosphate-buffered saline containing $0.1 \%$ Tween 20 (Sigma-Alrich) and 5\% low-fat milk (Boster Biological Technology, Ltd.) and incubated overnight at $4{ }^{\circ} \mathrm{C}$ with goat polyclonal $\mathrm{IgG}$ antibodies against human Notch1 (dilution, 1:400), Notch3 (dilution, 1:400) and GAPDH (I-19; catalog no. sc-48166; dilution, 1:2,000), which were all purchased from Santa Cruz Biotechnology, Inc. PVDF membranes were then incubated with a horseradish peroxidase-conjugated chicken anti-goat IgG secondary antibody (catalog no. sc-2953; Santa Cruz Biotechnology, Inc.; dilution, 1:2,000) for $1 \mathrm{~h}$ at room temperature. Immunoreactive bands were visualized using Luminol reagent (Boster Biological Technology, Ltd.) and a ChemiDoc $^{\text {TM }}$ XRS+ System with Image Lab ${ }^{\text {TM }}$ Software (BioRad Laboratories, Inc., Hercules, CA, USA).

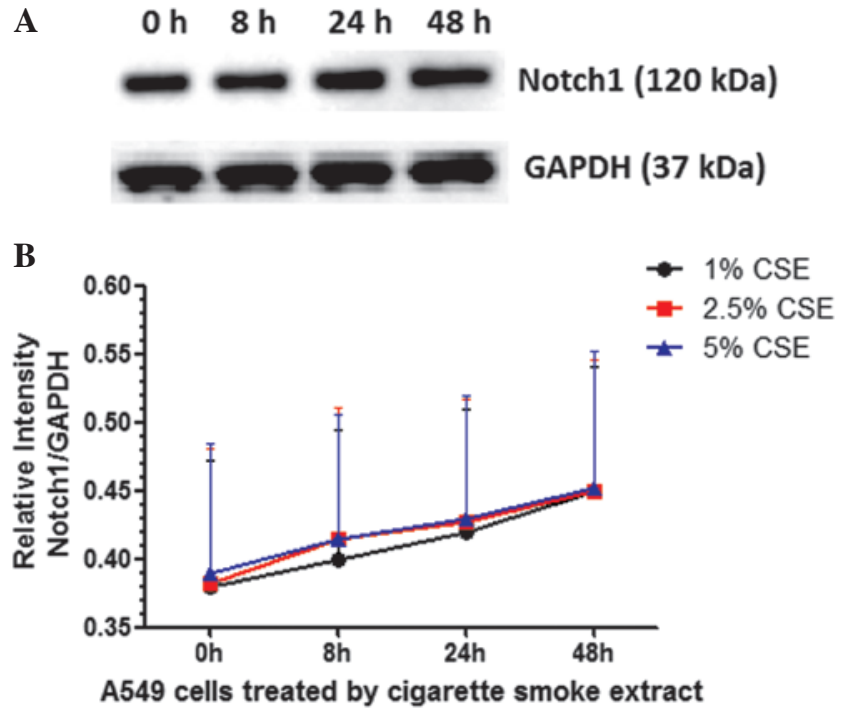

Figure 3. Protein expression of Notch1 in A549 cells was detected by western blot analysis. (A) Expression of Notch1 protein in A549 cells treated with 1\% CSE for $0,8,24$ and $48 \mathrm{~h}$. (B) A tendency chart revealing the expression of Notch1 protein at different time points in A549 cells treated by CSE $(1,2.5$ and $5 \%$ ). GAPDH was used as an internal control. Data are presented as the mean \pm standard deviation. No significant differences were found between the groups $(\mathrm{P}>0.05)$. CSE, cigarette smoke extract.

Statistical analysis. Clinical information is expressed as the median (range) for the morphological data. The group data are expressed as the mean \pm standard deviation. Differences between groups were analyzed using the $\chi^{2}$ test and a one-way analysis of variance for the functional data. $\mathrm{P}<0.05$ was considered to indicate a statistically significant difference between values. Statistical analyses were performed using GraphPad Prism 5 (GraphPad Software Inc., La Jolla, CA, USA). 
Table II. Expression of Notch1 and Notch3 in LAC tissue samples.

\begin{tabular}{|c|c|c|c|}
\hline Patients with LAC & Positive stain, $\mathrm{n}$ & Negative stain, $n$ & P-value \\
\hline Notch1 & & & 0.3318 \\
\hline Smokers & 18 & 34 & \\
\hline Non-smokers & 24 & 26 & \\
\hline Notch3 & & & 0.0165 \\
\hline Smokers & 38 & 14 & \\
\hline Non-smokers & 25 & 25 & \\
\hline
\end{tabular}

Smokers, $\mathrm{n}=52$; non-smokers, $\mathrm{n}=50$. LAC, lung adenocarcinoma.

A
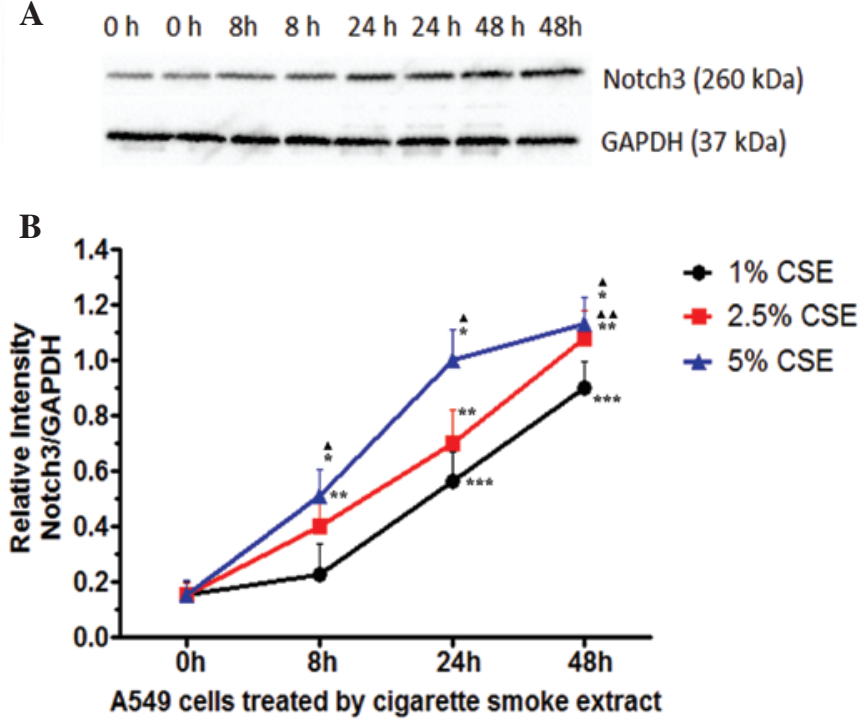

Figure 4. Protein expression of Notch3 in A549 cells was detected by western blot analysis. (A) Expression of Notch1 protein in A549 cells treated with $1 \%$ CSE for $0,8,24$ and $48 \mathrm{~h}$. (B) A tendency chart revealing the expression of Notch3 protein at different time points in A549 cells treated by CSE $(1,2.5$ and $5 \%$ ). GAPDH was used as an internal control. Data are presented as the mean \pm standard deviation CSE, cigarette smoke extract. ${ }^{*} \mathrm{P}<0.05$ vs. $5 \%$ CSE group (at $0 \mathrm{~h}$ time point). ${ }^{* *} \mathrm{P}<0.05$ vs. $2.5 \% \mathrm{CSE}$ group (at $0 \mathrm{~h}$ time point). ${ }^{* * *} \mathrm{P}<0.05$ vs. $1 \% \mathrm{CSE}$ group (at $0 \mathrm{~h}$ time point). ${ }^{\wedge} \mathrm{P}<0.05$ vs. $1 \% \operatorname{CSE}$ (at 8,24 and $48 \mathrm{~h}$ time points). ${ }^{\wedge} \mathrm{P}<0.05 \mathrm{vs} .1 \% \mathrm{CSE}$ (at $48 \mathrm{~h}$ time point).

\section{Results}

Immunostaining of Notch1 and Notch3 proteins in LAC. Notch1 and Notch3 were detected by immunohistochemistry (Fig. 1). The gray positive granules of Notch1 and Notch 3 were predominantly located in the cell membrane and cytoplasm of the tumor cells. Of the 102 lung cancer specimens, $42(41.2 \%)$ were positive for Notch1 and 63 $(61.8 \%)$ were positive for Notch3.

Correlation between Notch1 and Notch3 expression and cigarette smoking. As shown in Table II, there was no significant difference in the expression of Notch1 (positive rate and staining intensity) between smokers and non-smokers with LAC. The positive rate of Notch3 expression was higher in smokers compared with non-smokers. By comparing the intensities of positive staining, Notch3 was found to be more highly expressed in the smoking group than in the non-smoking group (134.7 \pm 70.4 vs. 82.6 \pm 44.6 , respectively; $\mathrm{P}=0.0012$ ). The effects of cigarette smoke on the expression of Notch1 and Notch3 according to gender and histological LAC subtype were not analyzed due to the limited sample size.

Cell viability following CSE treatment. The results of the Trypan blue exclusion test revealed that CSE significantly reduced the viability of A549 cells in a time-and dose-dependent manner at concentrations of $1 \%$ and $2.5 \%$ (Fig. 2; $\mathrm{P}<0.05$ ). At a concentration of $5 \% \mathrm{CSE}$, the cell viability was markedly reduced at $24 \mathrm{~h}$ compared with at 0 and $8 \mathrm{~h}(\mathrm{P}<0.05)$; however, there was no difference in the cell viability between $24 \mathrm{~h}$ and $48 \mathrm{~h}$ following the administration of $5 \%$ CSE $(\mathrm{P}>0.05)$.

Notch1 and Notch3 expression in A549 cells, as detected by western blot analysis. The expression of Notch1 and Notch3 in A549 cells treated with different concentrations of CSE was analyzed at continuous time points by western blot analysis. As shown in Fig. 3, the results revealed that the expression of Notch1 protein in A549 cells treated with CSE was relatively stable at different time points $(\mathrm{P}>0.05)$ and at various concentrations $(\mathrm{P}>0.05)$. As shown in Fig. 4, the expression of Notch3 in A549 cells increased in a time-and dose-dependent manner following treatment with CSE at concentrations of $1 \%$ and $2.5 \%(\mathrm{P}<0.05)$. The earliest peak of Notch3 protein expression was observed at $24 \mathrm{~h}$ following treatment with $5 \%$ CSE.

\section{Discussion}

It is estimated that $>300$ million people smoke cigarettes in China (20). Certain individuals do not stop smoking following the onset of respiratory symptoms due to an addiction to the tobacco; in addition, numerous patients continue to smoke cigarettes until a diagnosis of lung cancer has been established. In the present study, in order to identify the signaling pathways that are affected by cigarette smoke, stage II LAC samples were obtained from smokers and non-smokers; in addition, the effects of CSE on A549 cells were investigated. A previous study revealed that abnormalities in the Notch signaling pathway were associated with cigarette smoke in smokers and patients with chronic obstructive pulmonary disorder (COPD) (21). Recent studies have demonstrated that Notch1 and Notch3 have important roles in the pathogenesis 
of LAC (9-14). Therefore, the present study chose to analyze the expression of Notch1 and Notch3 proteins.

Zheng et al (22) reported that overexpression of Notch1 inhibited the growth of A549 cells and interfered with their ability to form tumors in nude mice. The results of a further study by Kluk et al (23) revealed that Notch1 was rarely activated in NSCLC specimens (detailed clinical data concerning LAC was not provided). Wael et al (24) demonstrated that blocking Notch1 in A549 cells resulted in increased cell proliferation. Furthermore, Huang et al (11) observed that negative Notch1 expression was significantly associated with advanced clinical stage and lymph node metastasis in LAC patients. However, increasing evidence indicates that Notch1 acts as an oncogene in LAC. A number of studies have investigated the association between the expression of Notch1 and its clinical significance and found that Notch1 may be used as a predictable biomarker for poor LAC prognoses $(9,10)$. In addition, Westhoff et al $(25)$ established that the activation of Notch1 was correlated with poor clinical outcomes in NSCLC patients not harboring TP53 mutations. Microenvironment hypoxia is common in LAC, where it supports cancer stem cell survival and results in poor responses to anticancer therapies (26-28). A study by Chen et al (29) demonstrated that hypoxia dramatically elevated the expression of Notch1 in lung tumor cell lines and that Notch1 was required for LAC cell survival under hypoxia. It has been reported that under a hypoxic microenvironment, Notch-1 activates Akt-1 through the inhibition of phosphatase and tensin homolog expression and the induction of the insulin-like growth factor 1 receptor (30). Several studies have revealed that A disintegrin and metalloproteinase (ADAM)17 (31), ADAM10 (32) and Galectin-1 (33) may contribute to the migration and invasion of LAC cells via the activation of Notch1. The activation of the Notch1 signaling pathway also has downstream effects on protein kinase casein kinase $2 \alpha$ (34), Ras (35) and tribbles homolog 3 (36). The activation of Notch1 may contribute to drug resistance in LAC, since the downregulation of Notch1 has been found to be effective during treatment with $\delta$-tocotrienol (37-39), gefitinib $(40,41)$, cisplatin (42) or pterostilbene (43). Blocking Notch1 has been identified to inhibit the growth of cluster of differentiation 133-positive cancer cells (44). The results of the present study demonstrated that there was no significant difference in the rate and intensity of Notch1 positive expression between the smokers and non-smokers with LAC. Huang et al (11) analyzed the expression of Notch1 in LAC and also did not establish any association between Notch1 and cigarette smoke; however, only 37 smokers were recruited in the study. In addition, the present study administered CSE to the LAC A549 cell line. The results of western blot analysis revealed that cigarette smoke did not affect the expression of Notch1 protein in LAC. In summary, Notch1 may be an important factor in the pathogenesis of LAC; however, in the present study, it was concluded that cigarette smoke did not affect the expression of Notch1 protein in LAC.

Notch 3 has also been identified to exhibit a correlation with LAC (45). Haruki et al (12) reported that the positive expression rate of Notch3 was $~ 37 \%$ (32/87) in LAC and indicated that its mechanism of maintaining the neoplastic phenotype may proceed via the modulation of the epidermal growth factor pathway. Additional studies have revealed that the protein expression of Notch3 was higher in NSCLC tissues $(13,14)$. Konishi et al (46) identified that the inhibition of Notch3 activation reduced the proliferation of A549 cells. A further study established that an elevated expression of Notch3 was present in aldehyde dehydrogenase (ALDH)-positive tumor cells and that the inhibition of Notch3 decreased the number of ALDH-positive tumor cells (47). However, none of these studies discussed the effect of cigarette smoke on the expression of Notch3 in LAC. In the present study, the positive staining rate $(73.1 \%)$ and the intensity of Notch 3 protein in the samples of LAC from smokers were significantly higher compared with those in the non-smokers. In addition, it was revealed that CSE was able to increase the expression of Notch3 protein in A549 cells in a time-and dose-dependent manner. Therefore it may be hypothesized that cigarette smoke promotes the pathogenesis of LAC via the Notch3 pathway.

In conclusion, the present study revealed that cigarette smoke promoted the expression of Notch3 protein, not Notch1 protein, in LAC. This differed to results obtained from patients with COPD and healthy smokers (21). This may be due to the fact that the Notch signaling pathway has different roles in different diseases. Further studies should be conducted in order to validate these results. Cigarettes contain $>60$ chemicals that have been identified as carcinogens $(48,49)$; therefore, studies that aim to identify the chemicals in cigarettes that may affect Notch3 are required. In addition, specific inhibitors of the Notch3 pathway may be investigated in future studies in order to clarify the effects of cigarette smoke on Notch3 expression.

\section{Acknowledgements}

This study was supported, in part, by a research grant from the National Natural Science Foundation of China (no. 81300031).

\section{References}

1. Stanley KE: Lung cancer and tobacco - a global problem. Cancer Detect Prev 9: 83-89, 1986.

2. Kadara H, Kabbout M, Wistuba II: Pulmonary adenocarcinoma: a renewed entity in 2011. Respirology 17: 50-65, 2012.

3. Harris CC: The epidemiology of different histologic types of bronchogenic carcinoma. Cancer Chemother Rep 4: 59-61, 1973.

4. Allen SS: Cigarette smoking among women: how can we help? Minn Med 97: 41-3, 2014.

5. Stellman SD, Muscat JE, Hoffmann D and Wynder EL: Impact of filter cigarette smoking on lung cancer histology. Prev Med 26: 451-456, 1997.

6. Hecht SS: Lung carcinogenesis by tobacco smoke. Int J Cancer 131: 2724-2732, 2012.

7. Wen J, Fu JH, Zhang W and Guo M: Lung carcinoma signaling pathways activated by smoking. Chin J Cancer 30: 551-558, 2011.

8. Galluzzo P and Bocchetta M: Notch signaling in lung cancer. Expert Rev Anticancer Ther 11: 533-540, 2011.

9. Donnem T, Andersen S, Al-Shibli K, Al-Saad S, Busund LT and Bremnes RM: Prognostic impact of Notch ligands and receptors in nonsmall cell lung cancer: Coexpression of Notch-1 and vascular endothelial growth factor-A predicts poor survival. Cancer 116: 5676-5685, 2010.

10. Jiang X, Zhou JH, Deng ZH, Qu XH, Jiang HY and Liu Y: Expression and significance of Notch1, Jagged1 and VEGF in human non-small cell lung cancer. Zhong Nan Da Xue Xue Bao Yi Xue Ban 32: 1031-1036, 2007 (In Chinese).

11. Huang J, Song H, Liu B, et al: Expression of Notch-1 and its clinical significance in different histological subtypes of human lung adenocarcinoma. J Exp Clin Cancer Res 32: 84, 2013.

12. Haruki N,Kawaguchi KS, Eichenberger S, et al: Dominant-negative Notch3 receptor inhibits mitogen-activated protein kinase pathway and the growth of human lung cancers. Cancer Res 65: 3555-3561, 2005. 
13. Zhou M, Jin WY, Fan ZW and Han RC: Analysis of the expression of the Notch3 receptor protein in adult lung cancer. Oncol Lett 5: 499-504, 2013.

14. Ye YZ, Zhang ZH, Fan XY, et al: Notch3 overexpression associates with poor prognosis in human non-small-cell lung cancer. Med Oncol 30: 595, 2013.

15. Shepherd FA, Crowley J, Van Houtte P, et al; International Association for the Study of Lung Cancer International Staging Committee and Participating Institutions: The International Association for the Study of Lung Cancer lung cancer staging project: proposals regarding the clinical staging of small cell lung cancer in the forthcoming (seventh) edition of the tumor, node, metastasis classification for lung cancer. J Thorac Oncol 2: 10671077, 2007.

16. Travis WD, Garg K, Franklin WA, et al: Bronchioloalveolar carcinoma and lung adenocarcinoma: the clinical importance and research relevance of the 2004 World Health Organization pathologic criteria. J Thorac Oncol 1: S13-S19, 2006.

17. Zhang L, Cheng Z, Liu W and Wu K: Expression of interleukin (IL)-10, IL-17A and IL-22 in serum and sputum of stable chronic obstructive pulmonary disease patients. COPD 10: 459-465, 2013.

18. Yin Y, Hou G, Li E, Wang Q and Kang J: PPAR $\gamma$ agonists regulate tobacco smoke-induced Toll like receptor 4 expression in alveolar macrophages. Respir Res 15: 28, 2014.

19. Strober W: Trypan blue exclusion test of cell viability. Curr Protoc Immunol Appendix 3: Appendix 3B, 2001.

20. Au WW, Su D and Yuan J: Cigarette smoking in China: Public health, science and policy. Rev Environ Health 27: 43-49, 2012

21. Tilley AE, Harvey BG, Heguy A, et al: Down-regulation of the notch pathway in human airway epithelium in association with smoking and chronic obstructive pulmonary disease. Am J Respir Crit Care Med 179: 457-466, 2009.

22. Zheng Q, Qin $\mathrm{H}$, Zhang $\mathrm{H}$, et al: Notch signaling inhibits growth of the human lung adenocarcinoma cell line A549. Oncol Rep 17: $847-852,2007$

23. Kluk MJ, Ashworth T, Wang H, et al: Gauging NOTCH1 activation in cancer using immunohistochemistry. PLoS One 8: e67306, 2013

24. Wael H, Yoshida R, Kudoh S, Hasegawa K, Niimori-Kita K and Ito T: Notch1 signaling controls cell proliferation, apoptosis and differentiation in lung carcinoma. Lung Cancer 85: 131-140, 2014.

25. Westhoff B, Colaluca IN, D'Ario G, et al: Alterations of the Notch pathway in lung cancer. Proc Natl Acad Sci USA 106 22293-22298, 2009.

26. Foster JG, Wong SC and Sharp TV: The hypoxic tumor microenvironment: driving the tumorigenesis of non-small-cell lung cancer Future Oncol 10: 2659-2674, 2014.

27. Graves EE, Maity A and Le QT. The tumor microenvironment in non-small-cell lung cancer. Semin Radiat Oncol 20: 156-163, 2010.

28. Maity A and Koumenis C: Location, location, location - makes all the difference for hypoxia in lung tumors. Clin Cancer Res 16 : 4685-4687, 2010.

29. Chen Y, De Marco MA, Graziani I, et al: Oxygen concentration determines the biological effects of NOTCH-1 signaling in adenocarcinoma of the lung. Cancer Res 67: 7954-7959, 2007.

30. Eliasz S, Liang S, Chen Y, et al: Notch-1 stimulates survival of lung adenocarcinoma cells during hypoxia by activating the IGF-1R pathway. Oncogene 29: 2488-2498, 2010.

31. Baumgart A, Seidl S, Vlachou P, et al: ADAM17 regulates epiderma growth factor receptor expression through the activation of Notch1 in non-small cell lung cancer. Cancer Res 70: 5368-5378, 2010.
32. Guo J, He L, Yuan P, et al: ADAM10 overexpression in human non-small cell lung cancer correlates with cell migration and invasion through the activation of the Notch1 signaling pathway. Oncol Rep 28: 1709-1718, 2012

33. Hsu YL, Wu CY, Hung JY, Lin YS, Huang MS and Kuo PL: Galectin-1 promotes lung cancer tumor metastasis by potentiating integrin $\alpha 6 \beta 4$ and Notch1/Jagged 2 signaling pathway. Carcinogenesis 34: 1370-1381, 2013.

34. Zhang S, Long H, Yang YL, et al: Inhibition of CK $2 \alpha$ down-regulates Notch1 signaling in lung cancer cells. J Cell Mol Med 17: 854-862: 2013.

35. Allen TD, Rodriguez EM, Jones KD and Bishop JM: Activated Notch1 induces lung adenomas in mice and cooperates with Myc in the generation of lung adenocarcinoma. Cancer Res 71: 6010-6018, 2011

36. Zhou H, Luo Y, Chen JH, et al: Knockdown of TRB3 induces apoptosis in human lung adenocarcinoma cells through regulation of Notch1 expression. Mol Med Rep 8: 47-52, 2013.

37. Ji X, Wang Z, Geamanu A, Sarkar FH and Gupta SV: Inhibition of cell growth and induction of apoptosis in non-small cell lung cancer cells by delta-tocotrienol is associated with notch-1 down-regulation. J Cell Biochem 112: 2773-2783, 2011.

38. Ji X, Wang Z, Geamanu A, Goja A, Sarkar FH and Gupta SV: Delta-tocotrienol suppresses Notch-1 pathway by upregulating miR-34a in nonsmall cell lung cancer cells. Int J Cancer 131: 2668-2677, 2012

39. Ji X, Wang Z, Sarkar FH and Gupta SV: Delta-tocotrienol augments cisplatin-induced suppression of non-small cell lung cancer cells via inhibition of the Notch-1 pathway. Anticancer Res 32: 2647-2655, 2012.

40. Xie M, He CS, Wei SH and Zhang L: Notch-1 contributes to epidermal growth factor receptor tyrosine kinase inhibitor acquired resistance in non-small cell lung cancer in vitro and in vivo. Eur J Cancer 49: 3559-3572, 2013.

41. Xie M, Zhang L, He CS, et al: Activation of Notch-1 enhances epithelial-mesenchymal transition in gefitinib-acquired resistant lung cancer cells. J Cell Biochem 113: 1501-1513, 2012.

42. Liu YP, Yang CJ, Huang MS, et al: Cisplatin selects for multidrug-resistant CD133+ cells in lung adenocarcinoma by activating Notch signaling. Cancer Res 73: 406-416, 2013.

43. Yang Y, Yan X, Duan W, et al: Pterostilbene exerts antitumor activity via the Notch1 signaling pathway in human lung adenocarcinoma cells. PLoS One 8: e62652, 2013.

44. Liu J, Mao Z, Huang J, Xie S, Liu T and Mao Z: Blocking the NOTCH pathway can inhibit the growth of CD133-positive A549 cells and sensitize to chemotherapy. Biochem Biophys Res Commun 444: 670-675, 2014.

45. Dang TP, Gazdar AF, Virmani AK, et al: Chromosome 19 translocation, overexpression of Notch3 and human lung cancer. J Natl Cancer Inst 92: 1355-1357, 2000.

46. Konishi J, Kawaguchi KS, Vo H, et al: Gamma-secretase inhibitor prevents Notch3 activation and reduces proliferation in human lung cancers. Cancer Res 67: 8051-8057, 2007.

47. Sullivan JP, Spinola M, Dodge M, et al: Aldehyde dehydrogenase activity selects for lung adenocarcinoma stem cells dependent on notch signaling. Cancer Res 70: 9937-9948, 2010.

48. Weiss W: Cigarette smoke as a carcinogen. Am Rev Respir Dis 108: 364-366, 1973.

49. Reif AE: Effect of cigarette smoking on susceptibility to lung cancer. Oncology 38: 76-85, 1981. 